\title{
Hr as Strategic Partner: Manpower- Engines of Change in Health Sector Reforms and Human Resource
}

\author{
Sanchita Raghav* \\ Faculty of Human Resource, Amity University Haryana, India
}

Submission: June 22, 2017; Published: August 10, 2017

*Corresponding author: Sanchita Raghav, Faculty of Human Resource, Amity University Haryana, India, Tel: +91 9717893731;

Email: sanchita.raghav21@gmail.com / sraghav@ggn.amity.edu

\section{Introduction}

Turnaround in healthcare strategy and human resource strategy knowledge insight aims to address expertise and insight about market overviews and management issues for top level management executives. Attempts are to be made to identify problems and propose solutions by referring to the fields of organisational operation and human resources development from various perspectives. The functions and performance of personnel are focussed on in terms of management resources. Complicated and advanced skills are required as per the careful selection of employees' desired functions. It is necessary to approach the healthcare strategies and human resources strategies essential for business management from a comprehensive perspective including both human nature and sociality. There is to some governance reform which focuses on managerial human resources.

Health care managers are entrusted by shareholders with the management of the health care organisation, but they sometimes conflict with shareholders. To solve such conflicts, healthcare organisations have health care leaders to provide oversight. However, this system cannot be expected to improve performance. It may be useful to separate execution of management transparency. This is not directly related to improving the performance of the organizational leaders.

Governance reform still does not address the issue of improving the skills of health care leaders themselves. Sore forming the control system merely changes its framework. Healthcare organisations must seek a way to improve the quality, capacity and actions of managerial human resources.

Human resources approach to developing management capability relies heavily on governance focusing on compliance also. Governance must be reformed for the following reasons: a. Enhance compliance

b. Improve the capacity of the board of directors to create corporate value.

The capacity to create corporate value by a member of the healthcare leaders means that they can maximise the value for stakeholders and improve performance. Compliance governance is equally important for taking effective measures to prevent fraud and misconduct by healthcare organisations or to improve management transparency [1]. Health care organisations are striving to reinforce their managerial human resources. Such initiatives include introducing a succession plan (for fostering managerial successors) for systematically and effectively cultivating newly promoted healthcare leaders and raising their skills.

\section{Reforming the Team Management of Healthcare Leaders: Hr Approach to Developing Management Capability}

In succession plan, candidates for management are selected at an early stage, exposed to various positions, and assessed or further promotion. The group is often reshuffled according to their performance in respective roles and opportunities. The main programs for improving the skills of existing organizational leaders are participation in outside seminars, director training by top management and in-house training by outside lecturers [2,3].

Below is a proposed model of programs for improving the skills of existing organizational leaders. The aims of these programs are to select candidates for board members, help them develop managerial skills, and improve their managerial capacity. To ensure that the healthcare leaders work well as a 
team, combined results of total personnel skills are raised. Sometimes, only negative aspects of the healthcare or group may

emerge such as ideas for partial optimisation, inward-looking attitude, and opportunity lost due to turf wars (Figure 1).

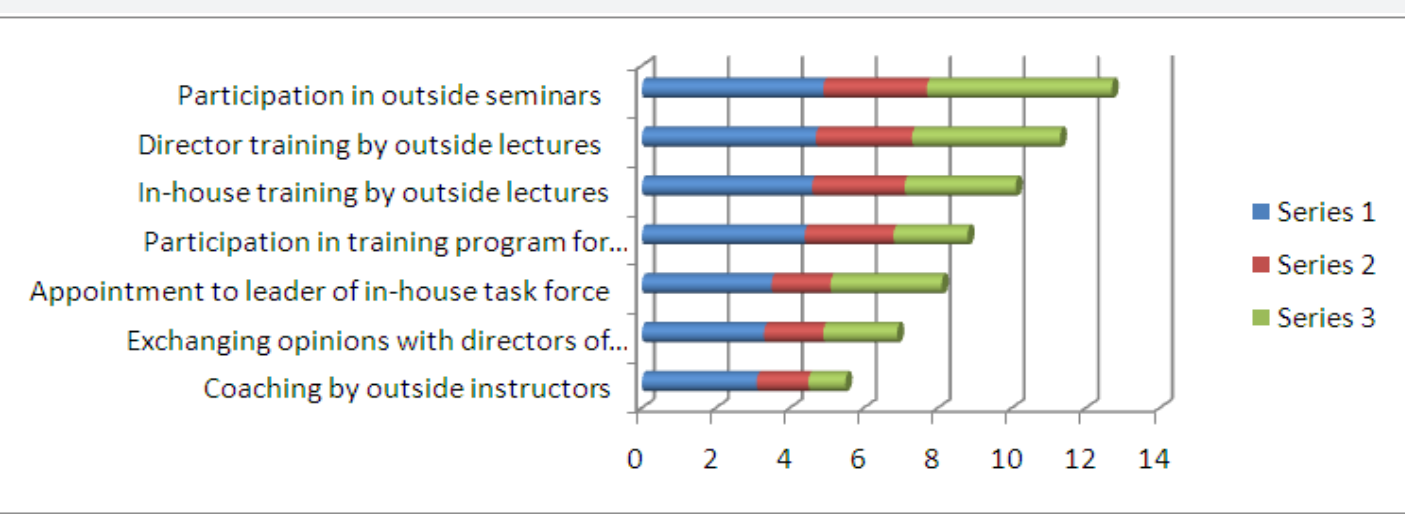

Figure 1: A dysfunctional management team may threaten the value of the health care organisation

Revitalising management members as a team can be done to enable the healthcare leaders or executive committee to function effectively as a team. These are as follows:

A. Objective Analysis of characteristics of the board of directors and executive committee. The process doing such analysis of identifying proposed equality objectives include progress made during previous financial year and the need to complete any outstanding actions, demographics of health care leaders as well as members, and characteristics of case work undertaken, root cause analysis reports, organisation's vision, values and strategic objectives.

B. Identification of impediments to teamwork. This is done based on the results of the objective analysis of decision making styles to identify how each healthcare leader hinders successful teamwork among the healthcare leaders or executive committee [4].

The healthcareleadersmustnotbeconsideredasa "sanctuary" in this analysis. Impediments are not limited to lack of daily communication or biased ideas based on their own divisions/ units. Examples are of power games, personal conflicts among organizational leaders or the responsibilities of the previous management members. If such impediments are discussed openly among the organizational leaders, the teamwork may begin to improve. Only an intensive, open-minded discussion can improve teamwork among the healthcare leaders [5]. To achieve this kind of analysis, a facilitator with no vested interests must preside over the group discussion, whose role is to create the environment for discussions and encourage participants to speak their minds. Examples of impediments to teamwork are such as various taboos (position of ownership, arguments on past management responsibilities or failures, sanctuary areas in management), limited time for activities and lack of sense o unity (lack of daily communication, lack of opportunities for understanding members' personalities, doubling as a leader of division), lack of rules and need for consensus(insufficient understanding of differences in contributions for each case, fewer remarks form organizational leaders other than top management due to lack of understanding), lack of maldistribution of information (over emphasis on achievement of division in charge, misuse of asymmetric information to serve own interests).

Redefinition of roles and achievements of the team. In compliance with this, health care organisations delegate decision making on important operations to the healthcare leaders. Details of legal actions must be taken in compliance with laws. It is important to specifically define the meanings of the expected achievements or performance of the health care leaders or executive committee. What targets do the healthcare leaders want to achieve to realize its management principles and visions, what they want to be are questions to ponder on. By developing a clear image on this, impediments to teamwork can be overcome. The health care leaders or executive committee must define their commitment to improving corporate value in their own words. This is a crucial step which sets the direction of their actions.

Implementation of the efforts required to form a capable team. After carrying impediments to teamwork, the performance expected out of healthcare leaders and executive committee, a capable team is to be formed. Specific efforts to do so are collectively implemented. These include initiatives to prevent the mal-distribution of information among the health care leaders and improve their mutual understanding. The first initiative is a health care leaders' meeting held every morning. All members except those on business trips must attend. This meeting helps participants to timely exchange information, thus eliminating the mal-distribution of information among them. The second initiative is cross-divisional appointment of task force leaders. The healthcare appoints a director as the leader of a task force unconnected to his own specialty. For example, a health care leader (director) in charge of personnel affairs appointed to unify product codes. These postings are expected to encourage reforms from a different viewpoint and improve mutual understanding among other healthcare leaders. Healthcare organisations must 
provide all its leaders with the opportunity to act as top leader to accelerate decision-making. Also, newly appointed health care leaders are entrusted with special missions unrelated to their specialty to change their focus from optimizing their own division to optimizing the healthcare as a whole. Higher leading authorities directly coach and support them, giving new leaders advice on private and business problems as necessary. Healthcare leaders and presidents of group organisations meet every month for something like a two-hour discussion on materializing the health care organisation's philosophy and visions. The purpose of such meetings is to reinforce the qualitative business base through discussions among management leaders. Specific topics include periodical assessment and improvement of corporate philosophy and visions, recognition and solution of qualitative management issues including corporate climate and motivation, and improvement of the corporate culture (Figure 2).

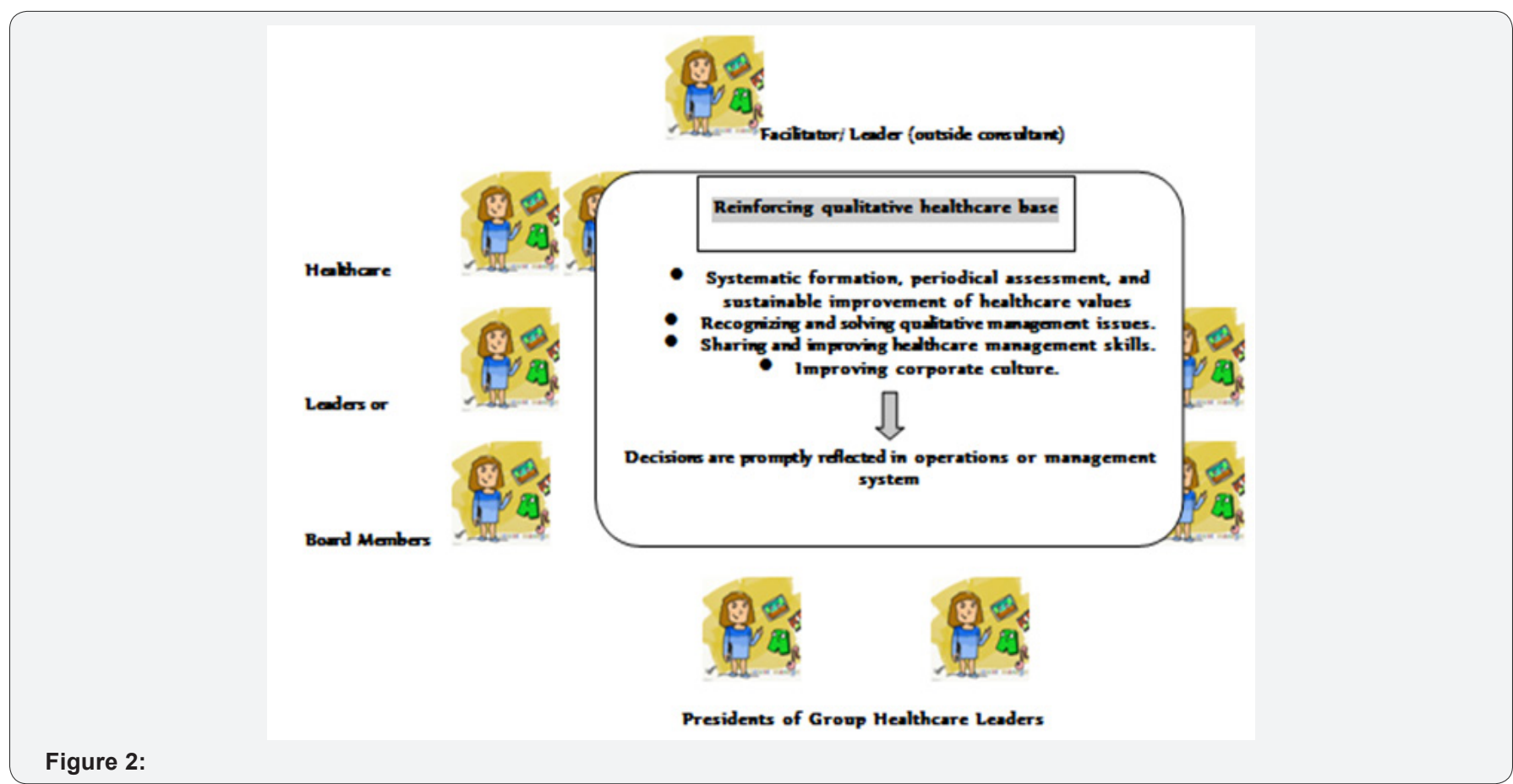

\section{Hr as Strategic Partner}

Human resource can be defined based on strategy-focussed, decision-focused, content-focused and implementation-focused approach. According to the strategy-focused approach, all human resource elements have strategic linkages. The decision-focused approach is based on decision making levels, namely, operational, managerial and strategic. According to the content-focused approach, human resource emerges when its elements match the healthcare's strategy. The implementation-focused approach refers to human resource systems that aid to the formulation and implementation of business strategies. The pattern of planned human resource depletions and activities are to intend to enable health care to achieve its goals. The differences in human resource strategies are based on the health care organisational types. These are defender, prospector, analyser and reactor. Make or buy human resource strategies focus on acquiring human resources. The human resource systems needed to align the human resources are the competitive strategies which include innovation, quality enhancement, and cost reduction strategy. The cost reduction strategy demands employees to hard harder, innovation strategy requires workers to work differently and quality strategy needs them to work smarter.
The human resource practices follow different patterns for different strategies. For instance, in case of innovation strategy, momentum is to be given for free thinking and bringing in new ideas. Performance appraisal focuses on long-term results. Employees are given opportunity to learn across functions and there are no clear cut job descriptions. For the development of cooperative culture, compensation offers more variety in terms of benefits like stock options and bonuses. Dynamic growth, extract growth and turnaround strategy are the paradigm strategies due to which human resource practices vary. It is not necessary that human resource strategy always conducts a give strategy. Such strategy can be proactive in contributing towards the strategy formulation, understanding the linkages between culture, strategy, human resource management and the strategy. During strategy plan formulation and implementation process, all functions contribute which leads to the development of various functional strategies including the human resource strategy. This includes creating future strategic alternatives like culture change, identifying mergers and acquisition possibilities, tracking the market and proactively making changes. The interactive effect between the business strategy and the human resource strategy conceptualises the integrative association [6]. 
Human resource practices in healthcare sector that have interactive effects bring out specific outcomes which aim at attracting the right kind of people, motivate them to perform optimally, and create a supportive climate and structure. Such linkage involves the connections created between and within people processes. Bringing out desired behaviours and culture in a healthcare organisation happens when there is an alliance of key human resource systems and processes. Such alliance practices bring out addictive outcomes. The influential factor of such alliance practices firstly includes the external environment, the business strategy that affects and is affected by the human resource process. Secondly, the health care organisational context within which the human resource operates comprising the human resource strategy and individual human resource practices and the outcomes of the process of human resource. Technological, economical, socio-cultural and political environment influence the strategy formulation of health care organisations. The apparent changes in these factors can be seen in better information processing, automation, changes in economic growth or growth in specific sectors, workforce demographics, and political influences. Factors affecting competitive strategy include industry structure, competitive advantage, economic conditions, product/market scope and the distinct competence. The labour market, skills and values, culture, economic conditions, government, media, environmentalists, consumer advocates and local community health care organisations help formulate human resource strategy. Current healthcare conditions and leadership roles affect the human resource strategy. The health care organisational culture and leadership include founder's vision, market and financial history, technological investments, regulations, unions, and competition. Long term human resource strategy is also influenced by the current human resource strategy. This means the anticipated environmental conditions shape the long term human resource strategy.

These conditions include technological changes, political, social and economic ambience. A number of health care organisationalfactors influence human resource strategy process. Alongside, there are barriers to effective human resource strategy. This first and foremost is top management does not include the human resource department in the decision-making process. Human resource adeptness is for administration, transactions, conformity and keeping complaints to a minimum. Human resource departments are to develop proficiencies in strategic issues, awareness and ability to quantify its own contributions. Comfort among human resource professionals to take risks, economic literacy among human resource professionals as well as their conviction about their principles are major barriers to effective human resource strategy. Knowledge of health care business, delivery of human resource, high degree of personal credibility and management of change are essential proficiencies of human resource. Cooperation of line managers is critical for human resource management. A closer relationship between human resource and line managers is required to increase the strategic importance of human resource. For issues concerning the employees the human resource managers should find more time to perform strategic functions related to human resource.

There are constraining factors like lack of training for devolved human resource responsibilities, lack of human resource aptitude in adequate time for people management issues, and short-term performance measures which cause lack of focus on achieving results through managing people. Human resource barriers include short term orientation of health care organisations, inability of human resource managers to think strategically, insufficient general management training, inability to influence colleagues in other departments, lack of appreciation, lack of cooperation from line managers and their unreliability in handling human resource functions, increased focus on quantifying results, feeling of risk in human resource investment hampers the development of the employees for complementing health care organisational performance, inability of human resource to change according to health care organisational needs, disincentives related to changes correlated to human resource management. Sometimes drastic changes in the workplace and other human resource processes need to be implemented. With the implementation of change there are difficulties and negative consequences of unsuccessful effort to change may obstruct the change processes of the future.

The periphery between sector reform and human resources in health care establishes the potential and actual impact of healthcare sector reform on the healthcare work force. Exploring individual and collective reactions to reform attempts by the employees is very thin on the ground. It is predominant to understand these reactions and their effects to assess whether reforms effectively reach their goals, since human resource factors can impede well designed reforms and thenceforward deprive populations of their potential benefits.

It is too narrow a view that human resources are commonly considered just another type of input, like physical or financial resources. Healthcare people are not singularly "instruments" which deliver necessitous health care. They are strategic thespians who are capable to act individually or collectively to modify projects, for instance trying to inhibit budget cuts which they present as a strategy to safeguard quality of services, blocking identical or equal deployment of resources in order to achieve a more rightful access to care.

The analysis of the connexions between these cogs provides an expedient tool to envisage the effects of different technical designs on the human resources they influence. This establishes the interface milieu of the relationships between the objectives and strategies of reforms of those who are anticipated to harness them. This will help identify the gaps in knowledge about the determinants of manpower participation, in the form of collaboration or opposition to systematic changes. The policy design indications of these interfaces assist to amalgamate 
human resource strategies into the healthcare reform process and to conceptualise a better uniform capacity for human resources development (Figure $3 \& 4$ ).
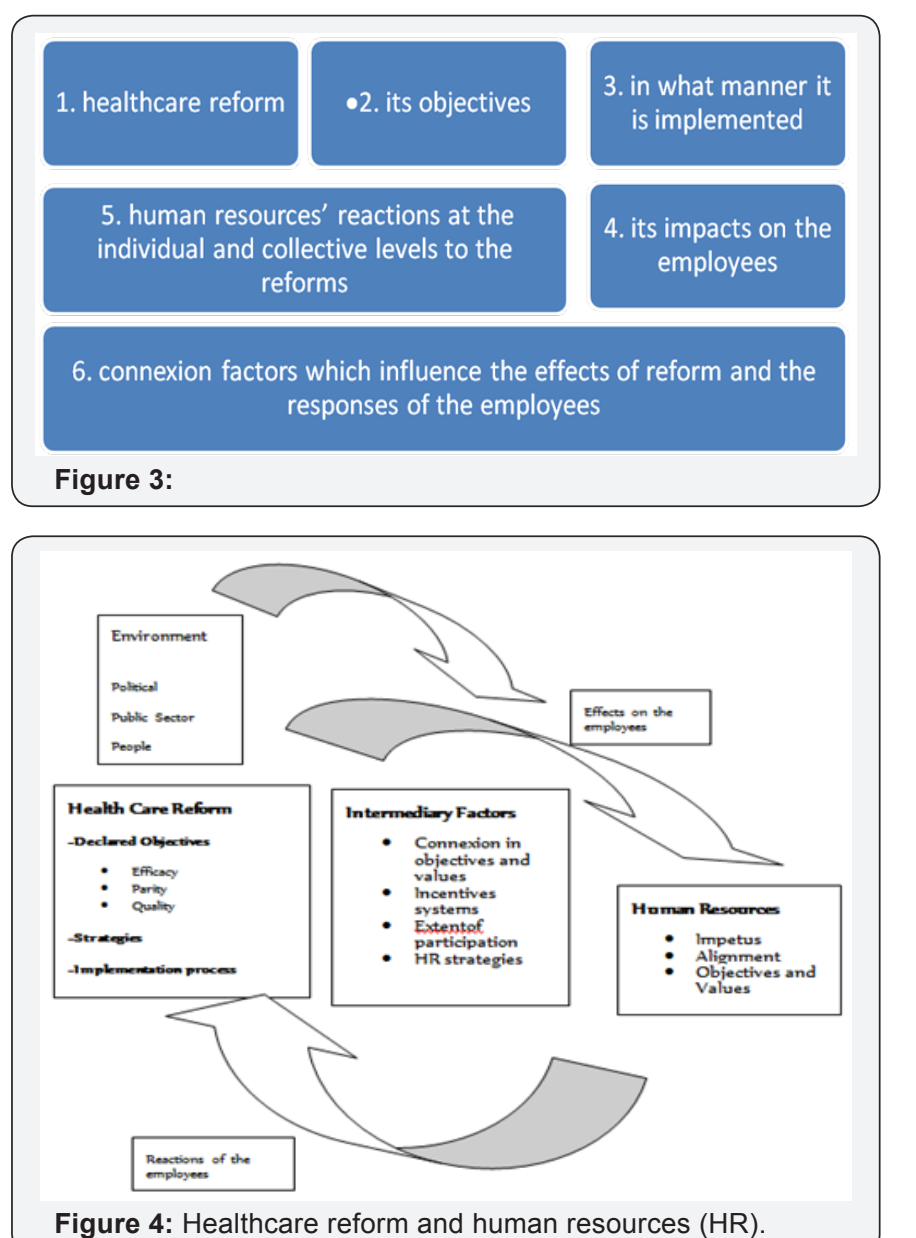

Manpower as Engines of Change

Human resource strategy process involves the formulation of healthcare strategy and translating it into human resource strategic objectives. Human resource systems are to be implemented on human resource strategy. Therefore, human resource strategy evolves from the human resource management strategic objectives. Through the evaluation and review of effectiveness and strategic integration of the human resource systems, the deterrent healthcare factors come in highlight whose presence or absence would inhibit the process of human resource management. The ground for human resource as strategic partner is made at the formulation stage. This helps the healthcare recognises human resource department as a proactive business partner. For this the team formulating the healthcare is composed.

Having the head of human resource department in the top team devising the healthcare strategy intensifies pro-active strategic linkage of human resource systems. Both interactive healthcare and human resource strategy contribute to the formulation of each other. Contexts, both organisational as well as external, influencing the strategy formulation include product market situation, nature, and extent of competition, labour market situation such as demography of the available workforce and laws, industry perspective, economy and forecasts, external stakeholders like suppliers, competitors. Healthcare situation is characterised by various departments as well as functions. Healthcare is formulated by the inputs from functional areas.

Human resource department head represents the healthcare in terms of human resource related issues. Other organisational contexts represented are the structural features, the proficiencies, cultural factors, policies and practices and manpower management issues. Required proficiencies are to be available in the human resource. This refers to the factors influencing the strategy formulation like possibility of training the employees for developing the required competencies. The required healthcare proficiencies are to be understood for the implementation of the health care strategy.

For ensuring the success of strategy implementation there is need for the acquisition, management and the development of the proficiencies. To understand the structure of the healthcare, the structural features synchronise the constraints in the changes required for the strategy implementation. Otherwise these features synchronise the limitations for strategy implementation. The rigidity in these features may inhibit departmental or functional alignment and communication for reporting structures, layers of hierarchy in the healthcare and formal relationship between the departments or functions. Organisation's top management can be appraised by the human resource head for formulating policies and practices which are followed and are necessary for effectual implementation of organisational strategy. These policies and practices may be related to jobs or behaviour in the organisation. This may also be related to the cultural dimensions' unwritten rules that drive the work culture and behaviour at work place.

Manpower management issues are related to employee related factors which directly affect productivity at the work place and their impact on healthcare strategy formulation. To this, there are some concerns regarding high turnover of employees, lack of morale and motivation, low employee satisfaction, work place politics etc. Human resource is to contribute to certain changes that occur in the labour market and their implications on the healthcare strategy formulation. Manpower strategic objectives are identified based on the healthcare strategy. Human resources strategic goals are identified according to the healthcare strategy. The healthcare strategy can be based on cost reduction, innovation or quality enhancement. Healthcare kinds can be classified as analyser, defender, prospector or reactor. Human resource strategic goals aid to the integration of the human resource strategy.

The implementation requirements are the roadblocks of human resource plan from strategic plan. This is followed by the implementation of various human resource systems based on the human resource strategy. These systems are typified on the 
basis of recruitment and selection, performance management, compensation, training and development, career management etc. which need to be aligned with the human resource strategy, initiating interventions required for organisational development or effectiveness and to manage change processes like restructuring or mergers. Such interventions deal with the sudden changes brought due to strategic decisions. Automation of human resource practices and their outsourcing contribute to effective functioning of human resource department. Through the use of human resource information system, the automation of human resource practices can be enhanced to collect and provide information required for strategy formulation. The processes and practices are implemented for the manpower. Therefore, line managers, employees and customers are significantly responsible for their successful implementation. Not only human resource systems are aligned with the human strategy, but these systems and their outcomes also disclose information pertaining to organisational context for the formulation of the organisational strategy [7]. This strengthens human resource as strategic partner.

The human resource systems' evaluation of its effectiveness and strategic integration is done by constructing the evaluation metrics. It is difficult to evaluate human resource systems because most of the health care organisations are not very clear as to what they want to evaluate. Healthcare organisations are not specific whether it is the efficiency of human resource processes or departments, human resource services, financial returns in terms of manpower productivity, turnover etc. or improved performance of manpower of the healthcare. To devise appropriate evaluation methods is difficult unless the expected outcomes are unambiguous. For constructing evaluation metrics, defining and measuring goal achievements or outcomes of human resources practices and activities is required. This includes health care organisational outcomes like manpower turnover, behavioural perspective of measuring the desired behaviour of employees, measuring achievement of desired proficiencies for the health care organisation. These outcomes are associated with performance reviews. Human resource systems are reviewed and analysed for their alignment to the strategic goals in order to determine the level of strategic integration. However, there are some constraints of the evaluation metrics. These include the implementation of human resource systems, efficiency of human resource processes and the level of competency of personnel involved in the implantation process. The evaluation of information collected and its analysis on the evaluation metrics offer feedback for making necessary changes in the implementation process and for the health care context of business strategy formulation. There are specific outcomes at different stages which may be different.

\section{Turnaround Facilitators/Disincentives}

Facilitators or disincentives are classified into structural cultural, individual and contextual factors. Structural factors refer to the absence or presence of representative of human resource and healthcare policies. Human resource is to be given a place in the strategy formulation which abets the representation of human resource for healthcare related issues. The presence or absence of such representation is a result of various factors which are significant for human resource regarding their ability to contribute to strategy formulation. It has been observed that top management teams differentiate between human resource executives and human resource function. Human resource executives are valuable members of strategic formulation team. The cultural factors include the importance given to human resource issues, top management support for human resource and human resource related issues. Human resource of healthcare is not only for providing support, it also has an active role in top management decision-making. Human resource function is an important factor of being reactive, in an operational role for the purpose of human resources integration with the healthcare's strategy. Following this is the crucial factors related to human resources representation in the strategic formulation team. These include the proficiency of human resource representatives in their respective field, their ability to represent efficiently, solid knowledge of the healthcare and the organisational context, awareness of the changes that are happening in the external context and their influence on the healthcare and the manpower issues. Other crucial factors are interpersonal dynamics in the representation process, ability of human resource to influence other representatives including the organisational leader, knowing the informal power structure for integrating the human resource with the organisational strategy.

Proficiencies required in top human resource professionals are classified as human resource technical proficiency, healthcare knowledge, influence management, functional and organisational leadership, and goal and action management. The contextual factors related to manpower management issues. These contextual factors are detrimental which arise unexpectedly in the organisation. Examples include very high employee turnover and severe skill shortage. In such situations, the top management is forced to notice human resource issues, which are generally neglected at other times.

Major facilitators or disincentives involved in the implementation have various influencing factors which are structural, cultural, operational and environmental. The structural factors include the human resource, various organisational policies regarding the roles to be played by the human resource. The healthcare of human resource deals with the staffing pattern of human resource, human resource personnel delegated roles, access of human resource to various other organisational units, the reporting structure within the human resource etc. Appropriate healthcare assuages in implementation and response to implementation related issues. The organisational policies regarding the human resource's participation provide guidelines for situations in which the human resource can intervene in the 
organisational functioning and the scope of changes that can be made there.

The choice of a particular turn around human resource strategy would be a function of the healthcare situation related to the health care organisation's market share and its capacity utilisation. This research paper is a discourse on the philosophy, process and strategies of human resource turnaround management in healthcare. It sheathes issues related to significance of strategic human resource turnaround management, its ingredients, diagnostic review, action choice and implementation framework for strategic human resource turnaround management and other dimensions of strategic human resource turnaround management in healthcare. The strategic movers of human resource turnaround management provide key insights drawn from functional as well as operational point of view to explain the strategic, change and implementation process and develop insights specific to the context. Such move contributes to devise, develop and implement human resource turnaround strategies for healthcare.

\section{References}

1. Rodgers EW, Wright PM (1998) Measuring organisational performance in strategic human resource management: problems, prospects Human Resource Management Review 8(3): 311-331.

2. Andrews R, George AB, Jennifer L, Richard M (2009) Walker; strategy, structure and process in the public sector: a test of the miles and snow model. Public Administration 87(4): 732-749.

3. David JH, Maurice AS (1980) Startegy follows structure. Strategic Management Journal 1(2): 149-163.

4. Cristiana BG, Julian B (2004) The antecedents, consequences, and mediating role of organisational ambidexterity. Academy of Management Journal 47(2): 209-226.

5. Cappelli P (2015) Why we love to hate hr. and what hr can do about it. Harvard Business Review, pp. 1-9.

6. Cross R, Prusak L (2002) The people who make organisations go-or stop. Harv Bus Rev 80(6): 104-112.

7. Ikojiro N (1991) The knowledge-creating company. Harvard Business Review, pp. 96-104.

\section{Your next submission with Juniper Publishers} will reach you the below assets

- Quality Editorial service

- Swift Peer Review

- Reprints availability

- E-prints Service

- Manuscript Podcast for convenient understanding

- Global attainment for your research

- Manuscript accessibility in different formats ( Pdf, E-pub, Full Text, Audio)

- Unceasing customer service

Track the below URL for one-step submission https://juniperpublishers.com/online-submission.php 